\title{
Altered sucking dynamics in a breastfed infant with Down syndrome: a case report
}

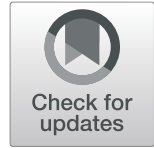

Viviane Silva Coentro, Donna T. Geddes and Sharon L. Perrella* (i)

\begin{abstract}
Background: The health and developmental advantages of human milk and breastfeeding are particularly important for infants with Down syndrome. However, they typically have shorter breastfeeding duration due to sucking issues that are not well understood. This case report describes serial measures of milk transfer volumes, sucking dynamics and tongue movement in a breastfeeding infant with Down syndrome. Management of maternal milk production enabled feeding of only breast milk until maturation of breastfeeding skills and the achievement of full breastfeeding by 6 months.

Case presentation: The mother of a term infant with Down syndrome and no associated health complications presented with concerns regarding adequacy of milk removal at the breast and low milk supply. We monitored sucking dynamics during breastfeeding by measuring intraoral vacuum strength, nutritive and non-nutritive suck rates and burst durations, and tongue movement using submental ultrasound. Breastfeeds were monitored at 4, 10, 14, 19 and 24 weeks, and maternal $24 \mathrm{~h}$ milk production was measured at 4, 10 and 24 weeks postpartum. We observed a weaker suck strength and shorter nutritive suck duration, and atypical tongue movement up to 19 weeks, with low milk transfer volumes. Regular breast expression was effective in increasing maternal milk production, providing expressed milk for all complementary feeds. Full breastfeeding was achieved by 6 months when reference sucking values were observed.

Conclusions: This case report illustrates that infants with Down syndrome may have low intraoral vacuum and limited nutritive sucking that persists for several months, likely due to delayed oro-motor development. In the absence of effective sucking human milk feeding can continue when milk production is stimulated with frequent and adequate breast expression. It is possible for infants with Down syndrome and no associated health complications to eventually establish full breastfeeding. Mothers that wish to breastfeed their infant with Down syndrome require anticipatory guidance and continuing lactation and family support.
\end{abstract}

Keywords: Breastfeeding, Sucking skills, Tongue movement, Down syndrome

\section{Background}

Down syndrome (Trisomy 21) is the most common chromosomal disorder with a reported incidence of 1 in 1100 Australian births, or 270 births per year [1]. Although the life expectancy of people with Down syndrome has increased over the last 30 years [2], the syndrome is associated with global developmental delay

* Correspondence: sharon.perrella@uwa.edu.au

School of Molecular Sciences, The University of Western Australia, M310, 35

Stirling Highway, Crawley 6008, Western Australia and impaired intellectual, immune, thyroid and sensory functions while congenital heart disease, gastrointestinal disorders, otitis media and obesity are common [3]. A relatively large tongue, hypotonia and atypical oro-motor development can contribute to speech and feeding difficulties with disorganised and dysfunctional sucking patterns reported [4-6]. For infants and children with Down syndrome and clinical signs of eating or drinking difficulty or suspected aspiration, the incidence of pharyngeal dysphagia and oral dysphagia is as high as 58

(c) The Author(s). 2020 Open Access This article is licensed under a Creative Commons Attribution 4.0 International License, which permits use, sharing, adaptation, distribution and reproduction in any medium or format, as long as you give appropriate credit to the original author(s) and the source, provide a link to the Creative Commons licence, and indicate if changes were made. The images or other third party material in this article are included in the article's Creative Commons licence, unless indicated otherwise in a credit line to the material. If material is not included in the article's Creative Commons licence and your intended use is not permitted by statutory regulation or exceeds the permitted use, you will need to obtain permission directly from the copyright holder. To view a copy of this licence, visit http://creativecommons.org/licenses/by/4.0/ The Creative Commons Public Domain Dedication waiver (http://creativecommons.org/publicdomain/zero/1.0/) applies to the data made available in this article, unless otherwise stated in a credit line to the data. 
and $64 \%$ respectively $[5,7]$. Silent aspiration and the risk of pneumonia is significantly higher in this population $[5,8]$. Breastfeeding is protective against respiratory and ear infections [9] and provides cognitive benefits [10]. As human milk has substantial beneficial impacts on health and development both in infancy and later in life, it is essential for optimisation of the lifetime health of infants with Down syndrome.

Shorter breastfeeding duration is reported for infants with Down syndrome, with a mean duration of 7.7 weeks compared to 23.4 weeks in healthy infants. Maternal reasons for weaning infants with Down syndrome include perceived low milk supply and poor infant suck [11]. Feeding difficulties are common and may be related to anomalies of oro-facial and nasomaxillary anatomy with altered reflexes and perioral hypotonia potentially impacting attachment and milk transfer at the breast [12].

Adequate intra-oral vacuum is fundamental to successful breastfeeding [13] yet there is no published data for sucking dynamics in breastfeeding infants with Down syndrome. Bottle fed infants with Down syndrome have a weaker suck and shorter suck bursts than age matched controls [14]. However sucking pressures, frequencies and efficiency are reported to improve over the first 12 months. Sucking dynamics differ between bottle and breastfeeding so these findings cannot be directly applied to the breastfed infant [15]. An understanding of the progression of feeding skills in infants with Down syndrome is critical to the development of evidence-based guidelines to support breastfeeding dyads. We present a longitudinal case report of breastfeeding characteristics and sucking dynamics in an infant with Down syndrome in the first 6 months.

\section{Case presentation}

The male infant was born at 38 weeks of gestation to a 32 year old primiparous mother. He developed respiratory distress within an hour of birth and was transferred to the neonatal intensive care nursery for treatment with supplemental oxygen. The infant was fed colostrum until resolution of respiratory symptoms on day two, when breastfeeding was initiated with use of a nipple shield to aid attachment. Three hourly breastfeeds were supplemented with infant formula or expressed breast milk $(\mathrm{EBM})$ and he was exclusively fed breast milk from day four. The parents were informed of the infant's clinical features of Down syndrome on the night of his birth and diagnosis was confirmed by genetic testing on day six. Associated health complications including congenital cardiac anomalies, thyroid disease and gastrointestinal malformations such as Hirschsprung's disease were not identified [3].
The family was discharged home with instructions to breastfeed and supplement with EBM every 3 h. At 3 weeks the mother was not confident of adequate milk transfer at the breast and concerned about continued use of a nipple shield to maintain attachment at the breast. She felt that her milk supply was reducing and sought help from an international board certified lactation consultant. After measurement of $24 \mathrm{~h}$ milk production, informed written consent was provided to participate in a longitudinal study of infant sucking dynamics, milk production and transfer. Studies were conducted at 4, 10, 14, 19 and 24 weeks.

At 4 weeks the infant was breastfeeding with a nipple shield and supplemented with EBM after most feeds. The infant was sleepy during both breast and bottle feeding. Chin support and dancer hand techniques [16] had been trialled to aid feeding but were not found to be helpful. Simultaneous breast expression was performed twice daily using a hospital grade electric breast pump. The $24 \mathrm{~h}$ milk profile confirmed low supply ie. $<600$ $\mathrm{mL} / 24 \mathrm{~h}$ [17] so expression frequency was increased. Nipple shield use was discontinued at 8 weeks due to a maternal sensation of nipple tightness.

As the mother was not confident of adequate milk transfer at the breast, an electronic baby scale was loaned so that the family could use test weights to guide supplementary feed volumes. Expressed breast milk supplements were given until 5 months. The mother aimed to feed the infant $800 \mathrm{~mL} / 24 \mathrm{~h}$. Using this strategy the infant maintained a pattern of weight gain considered adequate for male infants with Down syndrome (Fig. 1) [20]. The mother reported that test weighing was useful.

At the first visit, weak lip closure and compression without the application of intraoral vacuum was noted during digital examination. Sucking, rooting, gag and tongue thrust reflexes were present. The infant became fatigued during breastfeeding, but maintained an adequate seal and no swallowing difficulties were observed at all monitored breastfeeds. The mother reported that other than rare episodes of gagging, she did not observe any difficulties with swallowing. A speech therapist assessed the infant at 6 months and advised there were no signs of oral phase or pharyngeal phase dysphagia so family foods could be introduced.

The infant was regularly reviewed by a paediatrician and was treated for concurrent episodes of otitis media and urinary tract infection at 3 months. He was otherwise well, maintained adequate weight gain and had no clinical signs associated with aspiration and so was not investigated for this.

At 24 weeks the dyad was exclusively breastfeeding. The mother was confident of her infant's milk intake and enjoyed her breastfeeding experience. She now felt certain of achieving her initial goal of breastfeeding for 


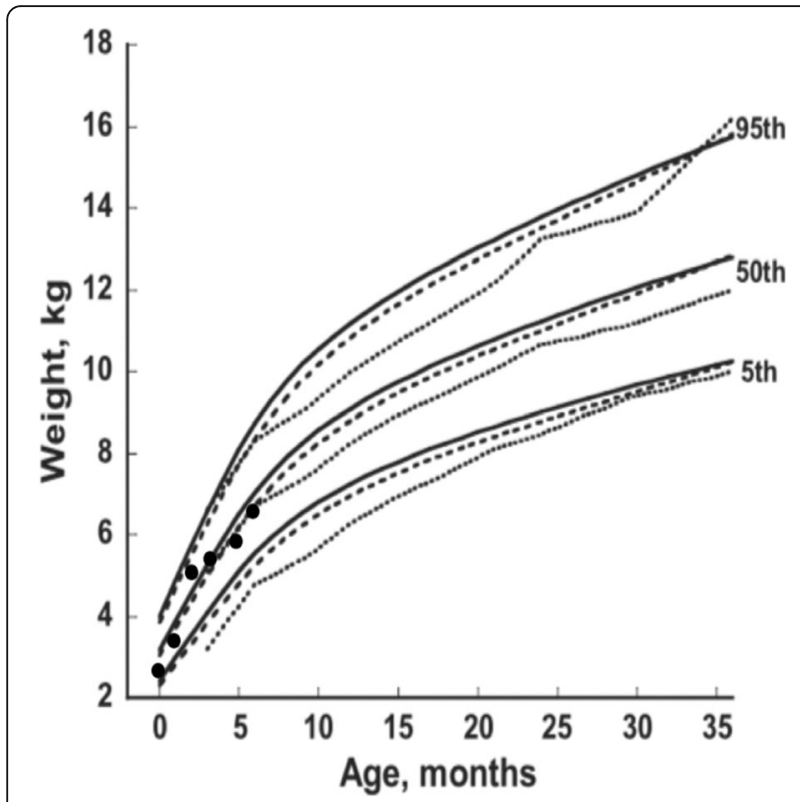

Fig. 1 Weight-for-age chart for a male infant with Down syndrome (Birth to 6 months). Legend: The infant's weight-for-age is plotted using black circles on growth curves for male children with Down syndrome from birth to 36 months of age. Contemporary growth curve is indicated by the solid line; previous published growth curves are indicated by a dotted line [18] and dashed line [19]. Growth curve chart is reproduced with permission from Dr. Babette Zemel [20]
12 months. Twice daily breast expression continued for the purpose of storing EBM for later use. First foods were gradually introduced from 6 months and breastfeeding continued until mutual weaning at 19 months.

\section{Summary of study findings}

The $24 \mathrm{~h}$ milk profile was obtained by recording infant test weights before and after each feed from each breast on an electronic scale (BabyWeigh, Medela Inc., McHerry IL, USA, resolution $2 \mathrm{~g}$, accuracy $\pm 0.034 \%$ ), and volumes of milk expressed and fed over a $24 \mathrm{~h}$ period [17]. Milk transfer volumes were recorded at each study visit [21]. Measurements expressed in grams were considered equivalent to $\mathrm{mL}$ [22]. While breastfeeding frequency and duration remained within the reference range, mean transfer volumes were low thereby requiring supplementation until 24 weeks (Table 1).

The $24 \mathrm{~h}$ milk production was low at 4 weeks and increased with regular breast expression. The infant received only breast milk through breastfeeding and EBM supplementary feeds from day 4 to 6 months of age, when consistent adequate milk transfer was achieved, allowing full breastfeeding.

Intra-oral vacuum was measured as previously described [13] with graphical representation of intra-oral vacuum used to measure sucking rate, bursts and pauses during monitored breastfeeds. Weak baseline and peak intra-oral vacuums were observed up to 19 weeks and were weaker with nipple shield use at 4 weeks. Reference value intra-oral vacuums, typically achieved by 4 weeks of age, were observed at 24 weeks (Table 2). Nutritive suck burst durations were shorter than reference up to

Table 1 Feeding characteristics in a breastfeeding infant with Down syndrome at 4, 10 and 24 weeks

\begin{tabular}{|c|c|c|c|c|}
\hline & 4 weeks & 10 weeks & 24 weeks & Reference range $[17,23]$ \\
\hline $24 \mathrm{~h}$ milk production $(\mathrm{mL})$ & 546 & 819 & 1150 & $788 \pm 169$ \\
\hline $24 \mathrm{~h}$ breastfeed frequency & 12 & 12 & 14 & $11 \pm 1.6$ \\
\hline Breastfeed duration (min) & 11 & 16 & 14 & $16(13,23.6)$ \\
\hline \multicolumn{5}{|l|}{ Breastfeed intake/feed (mL) } \\
\hline Left breast & $25(14,54)$ & $40(9,92)$ & $72(2,118)$ & $84 \pm 28^{a}$ \\
\hline Right breast & $19(12,28)$ & $32(10,56)$ & $60(16,114)$ & $67 \pm 26^{b}$ \\
\hline $24 \mathrm{~h}$ expression frequency & 6 & 7 & 0 & \\
\hline $24 \mathrm{~h}$ expression volume $(\mathrm{mL})$ & 278 & 392 & 226 & \\
\hline \multicolumn{5}{|l|}{$24 \mathrm{~h}$ infant milk intake $(\mathrm{mL})$} \\
\hline Breastfeeding & 268 & 427 & 924 & \\
\hline Expressed milk & 219 & 270 & 0 & \\
\hline Total milk intake & 487 & 697 & 924 & \\
\hline $\begin{array}{l}\text { Infant weight }(\mathrm{g}) \\
\text { (Birthweight }=2700 \mathrm{~g})\end{array}$ & 3478 & 5006 & 6425 & \\
\hline
\end{tabular}

Feeding characteristics reported as mean \pm standard deviation or median (min, max) for $24 \mathrm{~h}$ reference range, breastfeed duration and milk intake for left and right breasts. Measured values reported for the $24 \mathrm{~h}$ milk production, $24 \mathrm{~h}$ breastfeed frequency, $24 \mathrm{~h}$ expression frequency, $24 \mathrm{~h}$ expression volume and infant weight at monitored breastfeeds

avalues for more productive breast, ${ }^{b}$ Values for less productive breast 
Table 2 Sucking dynamics at 4, 10, 19, and 24 weeks in an infant with Down syndrome

\begin{tabular}{llllllll}
\hline Infant age & 4 weeks & 4 weeks & 10 weeks & 14 weeks & 19 weeks & 24 weeks & Reference range \\
\hline Breast & left & right (shield) & right & left & right & left & average \\
Peak vacuum (mmHg) & $-59 \pm 33.5$ & $-43 \pm 29$ & $-38.5 \pm 20$ & $-54 \pm 35$ & $-58 \pm 40$ & $-133 \pm 43$ & $-145 \pm 58[13]$ \\
Baseline vacuum (mmHg) & $-6 \pm 8$ & $-2 \pm 5$ & $0 \pm 4$ & $-6.5 \pm 11.5$ & $-12 \pm 18$ & $-31 \pm 30$ & $-64 \pm 45[13]$ \\
NS burst duration (s) & $3.3(0.4,8)$ & $2.3(1,10)$ & $3.8(0.6,19)$ & $3.7(0.5,17.5)$ & $4.5(0.7,20)$ & $6.0(0.4,75)$ & $8.9(4.5,18.3)[23]$ \\
NNS burst duration (s) & $2.0(0.5,2.7)$ & $2.7(2,8)$ & $1.6(0.6,7.5)$ & $2.5(0.5,10.5)$ & $5.0,(1,10.5)$ & $2.8(0.6,29.5)$ & $4.5(3.1,7.1)[23]$ \\
NP duration (s) & $2.3(0.6,35)$ & $3.0(0.5,41.2)$ & $1.4(0.3,19)$ & $1.0(0.6,76.5)$ & $0.9(0.5,9.1)$ & $0.7(0.4,99.6)$ & $2.9(1.8,5.5)[13]$ \\
NNP duration (s) & $3.5(1.7,13)$ & $16(2.6,48.7)$ & $2(0.3,37.5)$ & $2(0.7,128.2)$ & $18(0.9,67)$ & $2.3(0.6,19.5)$ & $2.7(1.9,4.0)[13]$ \\
Milk intake (mL) & 22 & 4 & 42 & 42 & 48 & 125 & $76(30-135)[17]$ \\
NS rate (sucks/min) & $101 \pm 22$ & $110 \pm 31$ & $87 \pm 17$ & $96 \pm 27.5$ & $97 \pm 22.5$ & $105 \pm 22.7$ & $74 \pm 17.1[23]$ \\
NNS rate (sucks/min) & $85.4 \pm 19$ & $112.3 \pm 22$ & $93 \pm 28.5$ & $105.4 \pm 20.3$ & $91.4 \pm 13$ & $118 \pm 33.2$ & $88.9 \pm 23.9[23]$ \\
Feeding efficiency (mL/min) & 4.7 & 1.5 & 6 & 6 & 8 & 11.5 & $8.9 \pm 4.2[24]$ \\
\hline
\end{tabular}

Sucking dynamics reported as mean \pm standard deviation or median (min, max) for peak and baseline vacuums, milk intake, nutritive (NS) and non-nutritive suck (NNS) rate and burst duration, nutritive (NP) and non-nutritive pause (NNP) duration and feeding efficiency at monitored breastfeeds for an infant with Down syndrome at 1-6 months of age

19 weeks, with a faster nutritive suck rate persisting across the first 6 months (Table 2) [23].

Sub-mental ultrasound imaging of the infant's intraoral cavity was performed at each study visit enabling a clear view of the nipple, tongue, hard palate, soft palate, and milk flow $[13,25]$. All ultrasound scans were performed for the duration of the breastfeed, beginning when the infant first attached to the breast. Ultrasound image measurements were made at tongue-up and tongue-down phases of nutritive sucking as described by McClellan [25]. Nipple placement was determined by measurement of the nipple hard-soft palate junction
(HPSPJ). The HPSPJ distance was not different and within reference range for tongue-up (5.6, 5.7, 6.2, 6.9 $\mathrm{mm})$ and tongue-down $(3.9,3.9,3.8,4.5 \mathrm{~mm})$ at $4,10,19$ and 24 weeks respectively indicating that attachment was maintained throughout suck bursts [25]. Reduced tongue movement was seen at 4 weeks, but not at subsequent visits (Fig. 2) where low intraoral vacuum was measured despite adequate downward displacement of the tongue.

\section{Discussion and conclusions}

This case report described low milk transfer volumes associated with low intra-oral vacuum and shorter

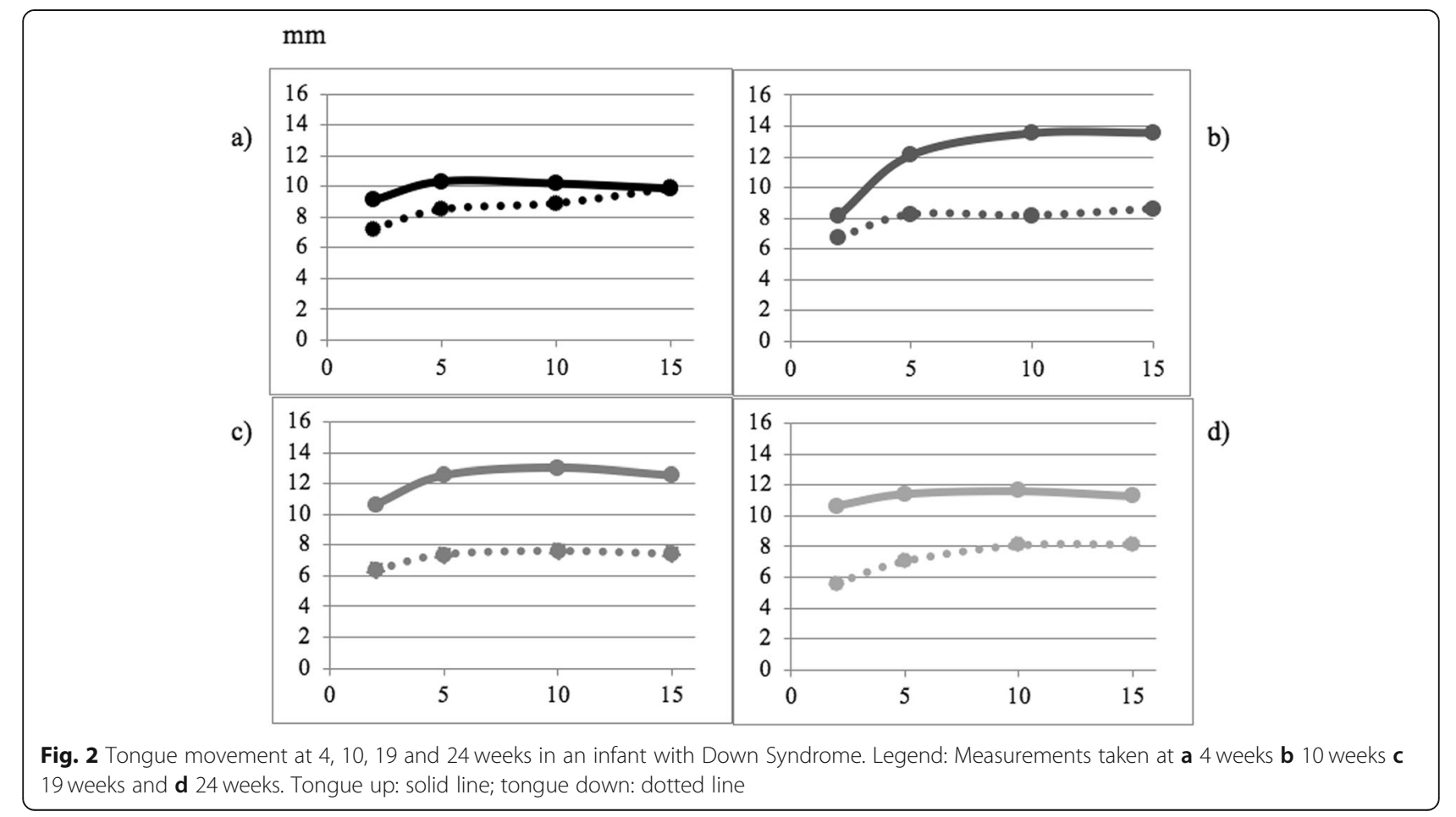


nutritive sucking bursts up to 20 weeks of age in a breastfed infant with Down syndrome. Exclusive breastfeeding was achieved by 24 weeks indicating a relationship between intra-oral vacuum, nutritive suck burst duration and milk transfer [23]. While the biomechanics of breastfeeding differ from that of bottle-feeding, our findings concur with the reported measures of low intraoral vacuum and feeding efficiency that increased over the first 8 months in fourteen bottle fed infants with Down syndrome [14]. Adequate breast attachment was maintained despite low baseline and peak vacuums so it is unlikely that external efforts to achieve or maintain attachment would be helpful. It has been established that infant intra-oral peak vacuum or negative pressure, is the primary mechanism of effective milk removal during breastfeeding. Generation of intra-oral vacuum increases with inferior displacement of the tongue and mandible [26]. We observed limited displacement of the tongue at 4 weeks but not subsequent to this. Weak intra-oral vacuum in the infants with Down syndrome has been attributed to oral hypotonia [12] which may impede the infant's ability to form an adequate seal with negative pressure (baseline vacuum) to facilitate milk transfer [14]. In a mouse model, when compared to nonsyndromic pups those with Down syndrome had reduced contractility in two oro-motor muscle groups that are involved in mandibular movement, with some improvement in only one group of muscles over time [27]. For newborn infants with Down syndrome weaker intraoral vacuum may be explained in part by reduced contractility of the oris orbicularis, masseter and/or buccinator muscles. It is likely that muscle strength and therefore mandibular oscillation and suck burst duration increase with enhanced neural recruitment and improved neuromuscular function that accompanies repeated use through feeding [28].

In the absence of an accurate clinical assessment tool for intra-oral vacuum during breastfeeding the perceived strength of suck on a gloved finger is used clinically. However, this may not reflect the infant's nutritive sucking action and strength during breastfeeding. The $24 \mathrm{~h}$ milk profile provides an accurate measure of milk transfer and production, and test weights at home can be used to guide supplementation. Indeed, regular test weighs of preterm infants during the establishment of breastfeeding is associated with earlier attainment of exclusive breastfeeding [29] and so may be a useful strategy for breastfeeding mothers of infants with Down syndrome.

Effective milk removal from the breast results from a combination of the application of adequate negative pressure and the positive pressure of milk ejection [13, $30,31]$. Both a higher degree of fullness of the breast and stronger negative pressure are associated with higher milk transfer volumes at the breast [32], so for infants with low intra-oral vacuum higher milk volume transfers can be facilitated with a higher $24 \mathrm{~h}$ milk production. Regular breast expression will be required to ensure adequate milk production and therefore promote breast fullness until maturation of infant sucking dynamics.

Infants with Down syndrome may have reduced breastfeeding effectiveness with delayed attainment of adequate intra-oral vacuum and suck burst duration. As regular breast expression and supplementation may be required for an extended period until typical sucking dynamics are achieved, anticipatory guidance and continuing support will likely benefit mothers that wish to breastfeed their infant with Down syndrome. Further studies of breastfeeding dynamics in infants with Down syndrome will elicit the range of developmental progression of intra-oral vacuum and suck burst duration in this population.

\section{Abbreviations}

EBM: Expressed breast milk; h: hour(s); HPSPJ: Hard palate soft palate junction; min: minute(s); $\mathrm{mL}$ : millilitre; $\mathrm{mm}$ : millimetre; $\mathrm{mmHg}$ : millimetre of Mercury; NNP: Non-nutritive pausing; NNS: Non-nutritive sucking; NP: Nutritive pausing; NS: Nutritive sucking; s: second(s); TU: Tongue up; TD: Tongue down; WHO: World Health Organization

\section{Acknowledgments \\ We wish to acknowledge the patient for her willing participation, and for her written consent to publication of the study. Medela AG funded the study through an unrestricted research grant. The University of Western Australia financed the cost of the article-processing charge.}

\section{Authors' contributions}

The majority of the work presented in this manuscript was completed by the author, VC. However, other authors contributed to this manuscript. VC reviewed the literature, performed data collection, acquisition analysis, interpretation of the data and has drafted the manuscript. DTG designed the study, reviewed the manuscript and provided feedback. SP designed the study, assisted with data collection and reviewed the manuscript and provided feedback. All authors have approved the submitted version of the manuscript and have agreed both to be personally accountable for the author's own contributions and accuracy or integrity of any part of the work.

\section{Funding}

VSC received a scholarship from Science without Borders, Government of Brazil. The salaries of SLP and DTG are paid from an unrestricted research grant paid by Medela AG to The University of Western Australia. The funding bodies were not involved in the study design, collection, analysis and interpretation of data, writing of the manuscript and the decision to submit the manuscript for publication. VC wrote the first draft of the manuscript and no honorarium, grant or other form of payment was given to any of the authors to produce the manuscript. The terms of this arrangement have been reviewed and approved by The University of Western Australia in accordance with its policy on objectivity in research.

\section{Availability of data and materials}

All data generated or analysed during this study are included in this published article (and its supplementary information files).

\section{Ethics approval and consent to participate}

The study was approved and granted by Ethics Committee of the Women and Newborn Health Service under the identification number: 2016034-EW and we obtained written consent from the participant. 


\section{Consent for publication}

Written informed consent for publication of participant clinical details and/or clinical images was obtained from the parent/guardian of the patient. A copy of the consent form is available for review by the Editor of this journal.

\section{Competing interests}

The authors declare that they have no competing interests.

Received: 10 February 2020 Accepted: 10 August 2020

Published online: 15 August 2020

\section{References}

1. Research and Statistics - Down Syndrome population statistics http://www. downsyndrome.org.au/research_and_statistics.html. Accessed 24 May 2017.

2. Bittles $A H$, Glasson EJ. Clinical, social, and ethical implications of changing life expectancy in Down syndrome. Dev Med Child Neurol. 2004;46(4):282-6.

3. Roizen NJ, Magyar Cl, Kuschner ES, Sulkes SB, Druschel C, van Wijngaarden E, Hyman SL. A community cross-sectional survey of medical problems in 440 children with Down syndrome in New York state. J Pediatr. 2014;164(4):871-5

4. Klingel D, Hohoff A, Kwiecien R, Wiechmann D, Stamm T. Growth of the hard palate in infants with Down syndrome compared with healthy infants - a retrospective case control study. PLoS One. 2017;12(8):e0182728.

5. Jackson A, Maybee J, Moran MK, Wolter-Warmerdam K, Hickey F. Clinical characteristics of dysphagia in children with Down syndrome. Dysphagia. 2016;31(5):663-71.

6. Harding C, Frank L, Botting N, Hilari K. Assessment and management of infant feeding. Infant. 2015;11(3):85-9.

7. O'Neill AC, Richter GT. Pharyngeal dysphagia in children with Down syndrome. Otolaryngol Head Neck Surg. 2013;149(1):146-50.

8. Weir K, McMahon S, Barry L, Ware R, Masters IB, Chang AB. Oropharyngeal aspiration and pneumonia in children. Pediatr Pulmonol. 2007:42(11):1024-31.

9. Victora CG, Bahl R, Barros AJ, Franca GV, Horton S, Krasevec J. Lancet breastfeeding series group. Breastfeeding in the 21st century: epidemiology, mechanisms, and lifelong effect. Lancet. 2016;387(10017):475-90.

10. Victora CG, Horta BL, Loret de Mola C, Quevedo L, Pinheiro RT, Gigante DP, Barros FC. Association between breastfeeding and intelligence, educational attainment, and income at 30 years of age: a prospective birth cohort study from Brazil. Lancet Glob Health. 2015;3(4):e199-205.

11. Pisacane A, Toscano E, Pirri I, Continisio P, Andria G, Zoli B, Vicari S. Down syndrome and breastfeeding. Acta Paediatr. 2003;92(12):1479-81.

12. Cooper-Brown L, Copeland S, Dailey S, Downey D, Petersen MC, Stimson C, Van Dyke DC. Feeding and swallowing dysfunction in genetic syndromes. Dev Disabil Res Rev. 2008;14(2):147-57.

13. Geddes DT, Kent JC, Mitoulas LR, Hartmann PE. Tongue movement and intra-oral vacuum in breastfeeding infants. Early Hum Dev. 2008;84(7):471-7.

14. Mizuno K, Ueda A. Development of sucking behavior in infants with Down's syndrome. Acta Paediatr. 2001;90(12):1384-8.

15. Goldfield EC, Richardson MJ, Lee KG, Margetts S. Coordination of sucking, swallowing, and breathing and oxygen saturation during early infant breastfeeding and bottle-feeding. Pediatr Res. 2006;60(4):450-5.

16. Thomas J, Marinelli KA, Academy of Breastfeeding Medicine. ABM clinical protocol \#16: breastfeeding the hypotonic infant. Breastfeed Med. 2016; 11(6):271-6.

17. Kent JC, Mitoulas LR, Cregan MD, Ramsay DT, Doherty DA, Hartmann PE. Volume and frequency of breastfeedings and fat content of breast milk throughout the day. Pediatrics. 2006;117(3):e387-95.

18. Cronk C, Crocker AC, Pueschel SM, et al. Growth charts for children with Down syndrome: 1 month to 18 years of age. Pediatrics. 1988;81(1):102-10.

19. Styles ME, Cole TJ, Dennis J, Preece MA. New cross sectional stature, weight, and head circumference references for Down's syndrome in the UK and Republic of Ireland. Arch Dis Child. 2002;87(2):104-8.

20. Zemel BS, Pipan M, Stallings VA, Hall W, Schadt K, Freedman DS, Thorpe P. Growth charts for children with Down syndrome in the United States. Pediatrics. 2015;136(5):e1204-11.

21. Arthur PG, Hartmann PE, Smith M. Measurement of the milk intake of breast-fed infants. J Pediatr Gastroenterol Nutr. 1987;6(5):758-63.
22. Casey CE, Hambidge KM, Neville MC. Studies in human lactation: zinc, copper, manganese and chromium in human milk in the first month of lactation. Am J Clin Nutr. 1985;41(6):1193-200.

23. Sakalidis VS, McClellan HL, Hepworth AR, Kent JC, Lai CT, Hartmann PE, Geddes D. Oxygen saturation and suck-swallow-breathe coordination of term infants during breastfeeding and feeding from a teat releasing milk only with vacuum. Int J Pediatr. 2012;2012:130769.

24. McClellan HL, Kent JC, Hepworth AR, Hartmann PE, Geddes DT. Persistent nipple pain in breastfeeding mothers associated with abnormal infant tongue movement. Int J Environ Res Public Health. 2015;12(9):10833-45.

25. McClellan HL, Sakalidis VS, Hepworth AR, Hartmann PE, Geddes DT. Validation of nipple diameter and tongue movement measurements with B-mode ultrasound during breastfeeding. Ultrasound Med Biol. 2010;36(11):1797-807.

26. Sakalidis VS, Williams TM, Garbin CP, Hepworth AR, Hartmann PE, Paech MJ, Geddes DT. Ultrasound imaging of infant sucking dynamics during the establishment of lactation. J Hum Lact. 2013;29(2):205-13.

27. Glass TJ, Connor NP. Digastric muscle phenotypes of the Ts65Dn mouse model of Down syndrome. PLoS One. 2016;11(6):e0158008.

28. Lewis E, Kritzinger A. Parental experiences of feeding problems in their infants with Down syndrome. Downs Syndr Res Pract. 2004;9(2):45-52.

29. Funkquist EL, Tuvemo T, Jonsson B, Serenius F, Nyqvist KH. Influence of test weighing before/after nursing on breastfeeding in preterm infants. Adv Neonatal Care. 2010;10(1):33-9.

30. Jacobs LA, Dickinson JE, Hart PD, Doherty DA, Faulkner SJ. Normal nipple position in term infants measured on breastfeeding ultrasound. J Hum Lact. 2007;23(1):52-9.

31. Elad D, Kozlovsky P, Blum O, Laine AF, Po MJ, Botzer E, Ben SL. Biomechanics of milk extraction during breast-feeding. Proc Natl Acad Sci U S A. 2014;111(14):5230-5.

32. Ramsay DT, Mitoulas LR, Kent JC, Cregan MD, Doherty DA, Larsson M, Hartmann PE. Milk flow rates can be used to identify and investigate milk ejection in women expressing breast milk using an electric breast pump. Breastfeed Med. 2006;1(1):14-23.

\section{Publisher's Note}

Springer Nature remains neutral with regard to jurisdictional claims in published maps and institutional affiliations.
Ready to submit your research? Choose BMC and benefit from:
- fast, convenient online submission
- thorough peer review by experienced researchers in your field
- rapid publication on acceptance
- support for research data, including large and complex data types
- gold Open Access which fosters wider collaboration and increased citations
- maximum visibility for your research: over $100 \mathrm{M}$ website views per year
At BMC, research is always in progress.
Learn more biomedcentral.com/submissions 